\title{
Sexual and Reproductive Health Services Utilization and Associated Factors Among University Students, Northwest Ethiopia: Cross Sectional Study
} \author{
Asmamaw $^{4}$ and Yohannes Ayanaw Habitu ${ }^{2 *}$ \\ ${ }^{1}$ Department of Health Systems and Policy, University of Gondar, Ethiopia \\ ${ }^{2}$ Department of Reproductive Health, University of Gondar, Ethiopia \\ ${ }^{3}$ Gender and HIV/AIDS mainstreaming Directorate, University of Gondar, Ethiopia \\ ${ }^{4}$ College of Medicine and Health science, University of Gondar, Ethiopia
}

Asmamaw Atnafu1, Adane Kebede1, Gizachew AssefaTessema², Kasahun Emiru ${ }^{3}$, Tinsae Berihun ${ }^{3}$, Tarekegn

Submission: May 28, 2019 ; Published: June 12, 2019

*Corresponding author: Yohannes Ayanaw Habitu, Department of Reproductive Health, University of Gondar, Ethiopia

\begin{abstract}
Introduction: Students in higher institutions of learning are exposed to diverse sexual and reproductive health problems, such as unintended pregnancies, Human Immuno Virus/Aquired Immuno Deficiency Syndrome, sexually transmitted infections, and unsafe abortions. Despite diverse efforts to improve student use of sexual and reproductive health services, there is still limited evidence on the level of university student use of the available sexual and reproductive health services at university set-ups. Therefore, this study aimed to assess sexual and reproductive health service utilization and associated factors among undergraduate university students in northwest Ethiopia.
\end{abstract}

Methods: An institution based cross-sectional study was conducted on undergraduate students at the University of Gondar in 2014.Data were collected using a pretested, structured, and self-administered questionnaire on 874 students selected by the multistage sampling technique. Data were entered and analyzed using SPSS version 20 statistical software, while Bivariable and Multivariable logistic regression models were used to identify factors associated with the outcome variable.

Results: The prevalence of sexual and reproductive health service utilization was $62.3 \%$, at a $95 \% \mathrm{CI}(54.1 \%, 68.7 \%)$. Students who discussed SRH issues with families [AOR=4.5 (CI: 2.42, 10.27)], lived in rural areas [AOR=1.60, 95\% (CI: 1.22, 2.16)], had better knowledge of SRH services $[\mathrm{AOR}=1.38(95 \% \mathrm{CI}: 1.94,2.03)]$, and had high risk perception for HIV infection [(AOR=1.80, 95\% CI $(1.58,1.10)]$ were significantly associated with sexual and reproductive health service utilization.

Conclusion: Sexual and reproductive health service utilization in the study area was found to be moderate. Factors like prior discussions of sexual and reproductive health issues, lived in rural areas, knowledge of sexual and reproductive health, level of risk perception for HIV/ AIDS were found to be associated with sexual and reproductive health services utilization. Therefore, interventions focused on such factors are recommended.

Keywords: Sexual Reproductive Health services; Utilization; University students; Ethiopia

Abbreviation: AIDS: Acquired Immune Deficient Syndrome; AOR: Adjusted Odds Ratio; CMHS: College of Medicine and Health Sciences; COR: Crude Odds Ratio; COCs: Combined Oral Contraceptives; ECs: Emergency Contraceptives; HCT: HIV Counseling and Testing, HIV: Human Immune Deficient Virus; IEC: Information Education and Communication; IPH: Institute of Public Health, SD: Standard Deviation; SRH: Sexual and Reproductive Health; STIs: Sexually Transmitted Infections; UoG: University of Gondar; VCT: Voluntary Counseling and Testing; WHO: World Health Organization

\section{Introduction}

The proportion of the youth is increasing tremendously on the globe [1,2]. Young people aged 10-24 years comprise over $27 \%$ of the world's population [1]. The majority of them live in developing countries [3], where HIV/AIDS and other sexual and reproductive health problems are widespread [1,2]. Globally, 15 million adolescents experience unwanted pregnancies each 
year $[4,5]$. According to the World Health Organization (WHO) report, nearly half of the induced abortions took place under unsafe conditions [4], and nearly all unsafe abortions (98\%) occur in developing countries [6]. Moreover, half of the new HIV infections are observed in the 15-24 age groups [7]. Each year, one in 20 adolescents suffers from STIs other than HIV [8.9].

In Ethiopia, adolescents and young people aged 10 to 24 years comprise about $30 \%$ of the population [10]. These people are disadvantaged in terms of having access to sexual and reproductive health information and services [10-13]. Gender inequality, sexual coercion, early sexual debut, unwanted/ unplanned pregnancy, adolescent pregnancy, abortion, sexually transmitted infections, and HIV/AIDS are the major youth sexual and reproductive problems in Ethiopia [11,12]. Several factors operating at individual, peer, family, school, and community levels fuel the sexual and reproductive health problems of youth in Ethiopia [9,14].

The majority of Ethiopian university students fall under the youth age group (15-24 years); thus, they are sexually active, and engage in mainly risky sexual behaviors [15]. Risky behaviors among undergraduate students may be aggravated by factors like decreased parental control, peer pressure, economic problems, and lack of youth friendly services [15]. Risky behaviors, particularly the consumption of alcohol, cigarette smoking, or the use of illicit drugs have been shown to be associated with increased risks of sexual intercourse, multiple sexual partners, and low rates of condom use $[15,16]$. The youth in universities usually lack access to information and health care services regarding sexual and reproductive health $[15,16]$. Also, are characterized by low sexual and reproductive health service utilization due to feelings of discomfort or fear of being seen by others at health care delivery points, and the embarrassment of seeking reproductive health services $[16,17]$. As a result, increasing access and utilization of health care relating to sexual and reproductive health, especially for the youth are high priority policy objectives in many countries [17]. Moreover, the provision of SRH services in universities is thought to be very effective in the prevention of students from developing various risky sexual behaviors and health related problems [18].

A study conducted in Kua Zulu, Natal, showed that even though the majority of students indicated to have awareness of VCT as an HIV/AIDS prevention method, only $37.9 \%$ utilized the services, whereas $43.9 \%$ utilized free condoms, $4.8 \%$ wellness Programs; 2\% Peer Education Programs and 0.6\% ART [19]. Another study conducted on Kenyan university students demonstrated that $76 \%$ somehow used the condom; only $18 \%$ of the males and $14 \%$ of the females confirmed to have used it every time they had sex; $89 \%$ had risk perception for HIV infection; $28 \%$ tested for HIV [20].

An Ethiopian study conducted at Medawolabou University showed that $80.5 \%$ of the study participants had used at least one reproductive health service [18]. Another study in Harar town of Ethiopia showed $64 \%$ of the respondents used at least one reproductive health service at the time of the survey [21]. A study at Debre Markos University showed SRH/VCT service utilization was 58.5\% among students [22]. Previous studies showed that VCT/SRH discussions with health care providers [22], information on health related services $[19,21]$, age, educational status, and occupation were some of the factors associated with sexual and reproductive health service utilization among young students [12].

Although exposed to any SRH problems, university student are on transformation to adulthood $[15,19,20]$. They also are on the process of building their academic and social carrier. As such, they are filled with lots of ambition. On top of that, what makes higher institution students different from the other youth is that they are confined to separate campuses, usually away from parents; they don't know where to go to get the services they need and have no money as well as time to go out for SRH services [23]. Although Ethiopia has developed a national youth policy in 2004, more effort is expected to satisfy the reproductive health care needs of university students [11]. Moreover, little has been explored about SRH service utilization and its associated factors in the context of Ethiopian Universities in general and the University of Gondar in particular. Therefore, this study was conducted to assess the SRH service utilization and associated factors among University of Gondar students.

\section{Materials and Methods}

\section{Study design and setup}

An institution based cross sectional study was conducted at the University of Gondar between May and June 2014.The University of Gondar is one of the 31 public universities in Ethiopia with more than 60 postgraduate and 30 undergraduate programs. According to the university registrar, more than twentyfive thousand students were enrolled by the 2014 academic year. The university has 5 campuses, namely the College of Medicine and Health Sciences (CMHS), Maraki, Tewodros, Fasil, and Tseda, with various colleges. Female students accounted nearly $50 \%$ of the total University enrollment. The University has five student clinics located in each of the campuses. In addition, there are Reproductive Health and Anti-HIV/AIDS clubs that aim at creating awareness on sexual and reproductive health issues among students.

\section{Source and study population}

All regular undergraduates were the source population, and all undergraduate students available during the study were the study population. All regular second year and above undergraduate students were included. Undergraduate students who were seriously ill and unable to respond to the questions as well as weekend and post-graduate students were excluded.

\section{Sample size and sampling procedure}

The sample size (884) was obtained by using the assumption that SRH service utilization of university students was $50 \%$ at 
a 95\% CI (as there has been no such investigation in the study setting), margin of error $5 \%$, design effect of 2 , and non response rate $10 \%$. Since the university has campuses, we allocated the sample to each campus using the multi-stage sampling procedure. Firstly, out of the 7 colleges and faculties in the university, 4 faculties were selected by the lottery method. Then, the simple random sampling technique was used to select 3-4 departments from each faculty. Then, proportional samples were allocated to each faculty considering the student population. Finally, all students in the selected departments were invited to participate.

\section{Data Collection Tools, Analysis, and Quality Assur- ance}

A structured and pre-tested questionnaire prepared in English and translated to the local language (Amharic) and then back to English was used for data collection. Three supervisors and ten data collectors participated in the process. After recruitment of data collectors and supervisors, a one-day intensive training was provided on the aim of the study, how to collect data, and clarification of the questionnaire before the actual task.

\section{Data processing and analysis}

The filled questionnaire was checked for completeness, cleaned manually, coded, and entered into EPI info version 3.5.3 statistical software and exported to SPSS windows version 20 for further analysis. Frequencies, proportions and summary statistics were used to describe the study population in relation to relevant variables and presented using tables and figures. The Bivariate analysis was employed primarily to check which variables had associations with the dependent variable. Then variables found to have $p$-values of less than 0.05 were entered the Multiple Logistic regression for controlling the possible effects of confounders. Finally, variables which had significant associations are identified on the basis of the Adjusted Odds Ratio (AOR) with a 95\%CI and at aP-value of 0.05 .

\section{Data quality control}

Data quality was assured by pre-testing the questionnaire on $42(5 \%)$ students in one department which was later excluded from the actual study. Training was given to data collectors and supervisors before the actual data collection day. The overall supervision was carried out by the chief investigators. The questions were reviewed and checked for completeness and consistency by supervisors and the principal investigator every day and necessary feedback was offered to data collectors in the next morning.

\section{Ethical considerations}

Ethical clearance was obtained from the Institutional Review Board of the University of Gondar after describing the purpose and objective of the study, and verbal \& written consent was obtained from each study participant. Participants were also informed that participation would be voluntary and that they could withdraw at any time they were not comfortable with the questionnaire. In order to maintain confidentiality, the information was gathered throughout with the exclusion of names as identifications by interviewing them separately.

\section{Results}

\section{Socio-demographic characteristics}

The response rate of this study was $98.9 \%$ (874/884). More than half $(56.1 \%)$ of the participants were female. The mean age of the respondents was 21year ( $\mathrm{SD}=1.98)$, and $476(54.5 \%)$ of them were below or equal to 20 years of age. With regard to their religion and ethnicity, 636 (72.8\%) were Orthodox Christians, and 489 (55.9\%) Amhara by ethnicity. The majority (97.5\%) of the students lived on the university campuses, (Table1).

Table 1: Socio-demographic characteristics of the respondents $(n=874)$, university of Gondar, Ethiopia, 2014.

\begin{tabular}{|c|c|c|}
\hline Variable & Frequency & Percent \\
\hline \multicolumn{3}{|l|}{ Sex } \\
\hline Male & 384 & 43.9 \\
\hline Female & 490 & 56.1 \\
\hline \multicolumn{3}{|l|}{ Age category } \\
\hline$<=20$ years & 476 & 54.5 \\
\hline $21-24$ & 347 & 39.7 \\
\hline$>=25$ & 51 & 5.8 \\
\hline \multicolumn{3}{|c|}{ Current Students Residence } \\
\hline In Campus & 852 & 97.5 \\
\hline Out of campus & 22 & 2.5 \\
\hline \multicolumn{3}{|c|}{ Faculty of Students } \\
\hline CMHS & 209 & 23.9 \\
\hline Maraki & 192 & 22 \\
\hline Tewodros & 249 & 28.5 \\
\hline Fasil & 224 & 25.6 \\
\hline
\end{tabular}




\section{Journal of Gynecology and Women's Health}

\begin{tabular}{|c|c|c|}
\hline Year of Study & & \\
\hline Year two & 359 & 41.1 \\
\hline Year three & 346 & 39.6 \\
\hline Year four & 159 & 18.2 \\
\hline Year five & 10 & 1.1 \\
\hline \multicolumn{3}{|l|}{ Marital Status } \\
\hline Not married & 801 & 91.6 \\
\hline Ever married & 73 & 2.4 \\
\hline \multicolumn{3}{|l|}{ Religion } \\
\hline Orthodox & 636 & 72.8 \\
\hline Muslim & 97 & 11.1 \\
\hline Protestant & 115 & 13.2 \\
\hline Others & 26 & 2.9 \\
\hline \multicolumn{3}{|l|}{ Ethnicity } \\
\hline Amhara & 489 & 55.9 \\
\hline Oromo & 146 & 16.7 \\
\hline Tigre & 102 & 11.7 \\
\hline Guragie & 63 & 7.2 \\
\hline Others & 74 & 8.5 \\
\hline \multicolumn{3}{|l|}{ Family Residence } \\
\hline Rural & 324 & 37.1 \\
\hline Urban & 550 & 62.9 \\
\hline \multicolumn{3}{|l|}{ Mother's Education } \\
\hline Unable read and write & 248 & 28.4 \\
\hline Read \& write & 250 & 28.6 \\
\hline Primary & 124 & 12.2 \\
\hline Secondary and above & 252 & 28.8 \\
\hline \multicolumn{3}{|l|}{ Father's Education } \\
\hline Unable read and write & 124 & 14.2 \\
\hline Read \& write & 293 & 33.5 \\
\hline Primary & 123 & 14.1 \\
\hline Secondary and above & 334 & 38.2 \\
\hline
\end{tabular}

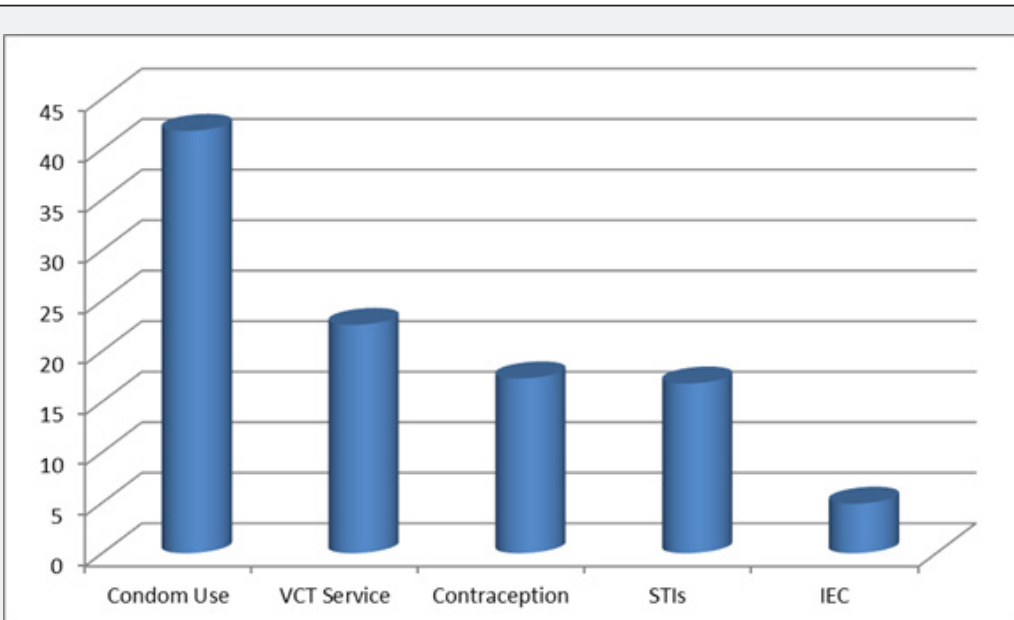

Figure 1: Common reasons why students visit the university SRH clinic, June 2014. 


\section{SRH service utilization and related characteristics}

All of the respondents were asked whether they had ever visited the university clinic or not, and more than half, 544(62.3\%) 95\%CI $(54.1 \%, 68.7 \%)$, said they visited the clinic for different reasons in the past one year. The main reasons for visiting the clinics were getting condoms, VCT service, contraception, STIs management, and Information Education and Communication (IEC) services from 220(40.4\%), 119(21.8\%), 91(16.7\%), 88(16.1\%), and 26(4.9\%), respectively (Figure1).

\section{Sexual and reproductive health knowledge}

Out of the total participants, 774 (90.4\%) had heard about SRH issues. The major sources of SRH information were the radio for 567 (37.9\%), followed by television for 515(34.4\%), posters for $256(17.1 \%)$, and magazines for $160(10.6 \%)$. The majority, $777(88.9 \%)$, of the participants reported they had already heard about STIs, and 671(37.0\%), 572(31.6\%), and 569(31.4\%) mentioned dysurea, genital ulcer, and genital discharge as the major symptoms for their visits, respectively. Regarding the methods they preferred for the prevention of HIV/AIDS, more than three-fourths, $759(36.0 \%)$, pointed out abstinence, while $696(33.0 \%)$ and $653(31.0 \%)$ chose faithfulness and condom use, respectively (Table2).

\section{Sexual and reproductive health related practices}

Regarding their previous sexual practice, 219(25.1\%) had sexual intercourse, of whom $214(97.7 \%)$ started before they joined the university, and $44(20.4 \%)$ used the condom. More than half of them, $141(64.4 \%)$, started sex with their boy/ girlfriends, and the mean age at first sex was 18 years (SD+2.2). Only $35(16.0 \%)$ and $30(14.0 \%)$ of the sexually active students had HIV counseling and testing (HCT) and STI screening and treatment services in that order. One hundred-sixty five (18.9\%) were sexually active during the last 12 months, of whom 81(49.1\%) had more than one sexual partners, and 95(57.6\%) used condoms during sex. Of all the respondents, 376(43.0\%) had high risk perception for HIV infection (Table 2).

Table 2: SRH knowledge and practice among students of University of Gondar, 2014.

\begin{tabular}{|c|c|c|}
\hline Variable & Frequency & Percentage \\
\hline \multicolumn{3}{|c|}{ Ever Heard of SRH 857} \\
\hline Yes & 774 & 90.4 \\
\hline No & 83 & 9.6 \\
\hline \multicolumn{3}{|c|}{ Source of SRH Information 1498} \\
\hline Television & 515 & 34.4 \\
\hline Radio & 567 & 37.9 \\
\hline Posters & 256 & 17.1 \\
\hline Magazine & 160 & 10.6 \\
\hline \multicolumn{3}{|c|}{ Ever Heard of Sties 874} \\
\hline Yes & 777 & 88.9 \\
\hline No & 97 & 11.1 \\
\hline \multicolumn{3}{|c|}{ Know STI Symptoms 1812} \\
\hline Dysuria & 671 & 37 \\
\hline Genital discharge & 569 & 31.4 \\
\hline Genital ulcer & 572 & 31.6 \\
\hline \multicolumn{3}{|c|}{ Know Contraceptive Methods 2406} \\
\hline ECPs & 572 & 23.8 \\
\hline COCs & 584 & 24.3 \\
\hline Condoms & 686 & 28.5 \\
\hline Loop & 564 & 23.4 \\
\hline \multicolumn{3}{|c|}{ Know HIV Prevention Methods 2108} \\
\hline Abstinence & 759 & 36 \\
\hline Faithfulness & 696 & 33 \\
\hline Condom use & 653 & 31 \\
\hline \multicolumn{3}{|c|}{ Ever had Sexual Intercourse 874} \\
\hline Yes & 219 & 25.1 \\
\hline No & 655 & 74.9 \\
\hline School Level at First Se & & \\
\hline
\end{tabular}


Journal of Gynecology and Women's Health

\begin{tabular}{|c|c|c|}
\hline University & 5 & 2 \\
\hline High school & 117 & 26 \\
\hline Secondary school & 57 & 18 \\
\hline Primary school & 40 & 64.4 \\
\hline First Sexual Partner 219 & 141 & 10.5 \\
\hline Boy/ girl friend & 23 & 14.2 \\
\hline Teacher & 31 & 3.2 \\
\hline Husband/wife & 7 & 5.9 \\
\hline Outside School or University & & 1.8 \\
\hline Business man/woman & 13 & \\
\hline Commercial sex worker & 4 & \\
\hline Yes & & \\
\hline No & 165 & \\
\hline Sexual Intercourse Within 12 Months 874 & 709 & \\
\hline No & & \\
\hline
\end{tabular}

\section{Factors associated with SRH service utilization}

Bivariable and Multivariable Logistic regression models were employed to determine factors associated with sexual and reproductive health service utilization (variables with p-value of $<0.05$ ). Students who had prior discussions on sexual and reproductive health issues had 4.5 times higher odds of utilization of sexual and reproductive health services $[\mathrm{AOR}=4.5$
(CI: 2.42, 10.27)] than those who had not. In addition, students from rural areas were about 1.6 times [AOR $=1.6,95 \%$ (CI: 1.22 , 2.16)] more likely to utilize reproductive health services than those from urban areas. Those who had good knowledge of SRH [AOR= 1.38 (CI: 1.94, 2.03)] and high risk perception for HIV infection [(AOR=1.80, CI $(1.58,1.10)]$ were also found to have significant associations with sexual and reproductive health service utilization (Table 3).

Table 3: Showing factors associated with SRH service utilization among UoG students.

\begin{tabular}{|c|c|c|c|c|c|}
\hline \multicolumn{2}{|c|}{ Variables } & \multicolumn{2}{|c|}{ SRH Service Use } & \multirow[t]{2}{*}{$\operatorname{COR}(95 \% \mathrm{CI})$} & \multirow[t]{2}{*}{ AOR(95\%CI) } \\
\hline & & Yes & No & & \\
\hline \multirow{3}{*}{ Age } & $15-19$ & 39 & 25 & $2.63(1.23,5.61)$ & $0.44(0.18,1.02)$ \\
\hline & $20-24$ & 469 & 290 & $2.72(1.52,4.90)$ & $0.43(0.22,1.82)$ \\
\hline & $\geq 25$ & 19 & 32 & 1 & 1 \\
\hline \multirow{2}{*}{ Sex } & Male & 237 & 147 & $1.11(0.85,1.46)$ & $0.80(0.58,1.14)$ \\
\hline & Female & 290 & 200 & 1 & \\
\hline \multirow{2}{*}{ Residence(students) } & In campus & 513 & 339 & $0.87(0.36,2.08)$ & $1.21(0.47,3.11)$ \\
\hline & Outside campus & 14 & 8 & 1 & \\
\hline \multirow{4}{*}{ Faculty of students } & CMHS & 111 & 98 & $1.00(0.69,1.46)$ & $1.19(0.77,1.84)$ \\
\hline & Social sciences & 131 & 60 & $1.93(1.29,2.88)$ & $0.69(0.38,1.97)$ \\
\hline & Business \&economics & 166 & 83 & $1.77(1.22,2.56)$ & $0.63(0.40,1.00)$ \\
\hline & Technology & 119 & 105 & 1 & 1 \\
\hline \multirow{2}{*}{ Marital status } & Un married & 482 & 319 & $0.94(0.58,1.54)$ & $0.94(0.55,1.58)$ \\
\hline & Ever married & 45 & 28 & 1 & 1 \\
\hline \multirow{3}{*}{ Year of study } & Year two & 228 & 131 & $1.23(0.85,1.789$ & $1.05(0.65,1.67)$ \\
\hline & Year three & 200 & 146 & $0.97(0.67,1.41)$ & $1.22(0.78,1.88)$ \\
\hline & Year four and above & 99 & 70 & 1 & 1 \\
\hline
\end{tabular}


Journal of Gynecology and Women's Health

\begin{tabular}{|c|c|c|c|c|c|}
\hline \multirow{2}{*}{ SRH knowledge } & knowledgeable & 78 & 63 & $1.28(0.89,1.84)$ & $1.38(1.94,2.03)^{* *}$ \\
\hline & Poor Knowledge & 449 & 284 & 1 & 1 \\
\hline \multirow{2}{*}{ Family residence } & Rural & 194 & 130 & $0.97(0.74,1.29)$ & $1.60(1.22,2.35)^{* *}$ \\
\hline & Urban & 333 & 217 & 1 & 1 \\
\hline \multirow{4}{*}{ Mother's education } & Unable read and write & 163 & 85 & $1.44(1.00,2.07)$ & $0.78(0.44,1.39)$ \\
\hline & Read and write & 153 & 97 & $1.18(0.83,1.69)$ & $1.00(0.61,1.67)$ \\
\hline & $1-8^{\text {th }}$ grade & 67 & 57 & $0.88(0.57,1.36)$ & $1.14(0.70,1.86)$ \\
\hline & $9-12^{\text {th }}$ grade & 144 & 108 & 1 & 1 \\
\hline \multirow{4}{*}{ Fathers education } & Unable read and write & 80 & 44 & $1.31(0.86,2.01)$ & $0.77(0.40,1.43)$ \\
\hline & Read and write & 192 & 101 & $1.37(0.99,1.90)$ & $0.78(0.46,0.31)$ \\
\hline & $1-8^{\text {th }}$ grade & 61 & 62 & $0.71(0.47,1.08)$ & $1.45(0.88,2.38)$ \\
\hline & $9-12^{\text {th }}$ grade & 194 & 140 & 1 & 1 \\
\hline \multirow{3}{*}{ Family income } & High & 52 & 42 & $0.72(0.43,1.21)$ & $1.35(0.776,2.89)$ \\
\hline & Middle & 377 & 248 & $0.88(0.62,1.27)$ & $1.18(0.75,1.67)$ \\
\hline & Low & 98 & 57 & 1 & 1 \\
\hline \multirow{2}{*}{ SRH Discussion } & Yes & 118 & 10 & $5.41(3.82,11.38)$ & $4.50(2.42,10.27)^{*}$ \\
\hline & No & 123 & 52 & 1 & 1 \\
\hline \multirow{2}{*}{$\begin{array}{l}\text { Risk Perception } \\
\text { towards HIV/AIDS }\end{array}$} & Yes & 237 & 147 & $1.46(1.11,1.85)$ & $1.80(1.58,1.10)^{*}$ \\
\hline & No & 290 & 200 & 1 & 1 \\
\hline
\end{tabular}

\section{Discussion}

This study showed the prevalence and factors associated with sexual and reproductive health service utilization among university students. The level of SRH service utilization was found to be $62.3 \%$, with $95 \%$ CI $(54.1 \%, 68.7 \%)$. The result is similar with that of a study conducted in Harrar (64.0\%) [21]. The level of SRH service utilization in this study was higher than those of studies conducted in Nepal (9.2\%) [23], Bahir Dar (32.0\%) [24], and Jimma (34.7\%) [25]. The possible justification for the different findings could be the presence of discrepancies in the study setups. For instance, if we compare the current study with those of Nepal and Bahir Dar, the study conducted in Nepal was on secondary school students and the Bahir Darstudy was on high school students, while this study was on university students. University students may have better knowledge regarding SRH issues and the places they get the services are likely to be more accessible compared to secondary and high school students. Since the study in Jimma took place in 2004 and ours in 2014, there is a time gap of ten years between the two works which might have brought about differences not only in participant awareness but also in the availability and accessibility of services, resulting in variations in the two findings.

Our finding is lower than that of a study conducted in Medawolabo uuniversity (80.5\%) [18]. The possible justification could be the difference in the proportion of sexually active participants in the two studies. In the Medawolabou study, $40.3 \%$ of the study participants were sexually active during the time of the study compared to $18.9 \%$ in this study. Sexually active students use SRH services more frequently because they need condoms, family planning services, and STIs diagnosis and management.

Students from rural areas were about 1.6 times $[\mathrm{AOR}=1.6$, 95\% (CI: 1.22, 2.16)] more likely to utilize reproductive health services than those from urban areas. The possible justification might be that most students from rural areas may practice sex for the first time on the campuses, and need help about SRH issues from campus clinics, whereas students from urban areas may practice sex earlier (had history of previous SRH service use) and they might not seek help from the student clinics that is, they may go to other SRH clinics out of university campus.

Students who had discussions on sexual and reproductive health issues were 4.5 times more likely to utilize sexual and reproductive health services $[\mathrm{AOR}=4.5$ (CI: 2.42, 10.27)] compared to those who had not. This is in agreement with studies conducted in Jimma [25] and Medawolaboue [18]. The possible reason might be that having discussions on SRH issues may build student confidence and help them to expose their SRH health concerns, get information from where they get services and are thus more likely to use services.

Participants who had enough knowledge on SRH services were more likely to utilize the services compared to those who had poor knowledge. This finding is in line with those of studies conducted in Debre Markos [22], Harrar [21], and Jimma [25]. Enough knowledge about SRH services could increase SRH service utilization may be the possible explanation for the finding. 
Students who had a high level of risk perception for HIV/ AIDS were found to have significant associations with sexual and reproductive health service utilization. This finding is supported by those of studies conducted in Debre Markos [22], Harrar [21], andJimma [25]. The possible explanation may be that having a high level of risk perception for HIV/AIDS might push students to know their HIV status and seek VCT services which increases their SRH service utilization.

\section{Conclusion}

Sexual and reproductive health service utilization in the study area was found to be moderate. Factors like prior discussions on sexual and reproductive health issues, rural life, knowledge of SRH, and level of risk perception for HIV/AIDS were associated with sexual and reproductive health service utilization. Therefore, concerned bodies are called upon to work on the factors identified. Causality could not be ascertained due to the cross-sectional nature of the study. In addition, the result can only be generalizable to university students. Therefore, we highly recommend further studies on out of school and in school youth, including university students.

\section{Declarations}

\section{Ethics approval and consent to participate}

Ethical clearance was obtained from the institutional review board (IRB) of Institute of Public Health, University of Gondar. Permission was obtained from each college Authorities. Informed consent was obtained from each study subjects. Respondents were also informed about their right to refuse or discontinue participation at any time. Information was recorded anonymously to maintain respondent's confidentiality and privacy.

\section{Availability of data and material}

All the dataset supporting the conclusions of this article are included within the article.

\section{Competing interests}

The authors declare that they have no conflicts of interest in this work

\section{Authors' Contributions}

AA, AK, GAT, KE, TB, YAH and TA were involved in study conception, design, coordination, data collection, data analysis, interpretation, and write up. YAH was involved in data analysis, write up and prepared the manuscript. All authors read and approved the final manuscript.

\section{Acknowledgements}

The authors would like to acknowledge all the study participants, the data collectors, and supervisors, for participation in the study. We also acknowledge authorities of UoG, IPH for ethical approval.

\section{References}

1. (2013) UN, World population prospects: the 2012 revision. World population prospects, Population Division of the Department of Economic and Social Affairs of the United Nations Secretariat, New York, USA.

2. www.un.org/esa/population/publications/wpp2008/wpp2008_ highlights.pdf

3. http://www.prb.org/pdf12/status-reportyouth-subsaharan-Africa. pdf

4. Shah I, Áhman E (2010) Unsafe abortion in 2008: global and regional levels and trends. Reprod Health Matters 18(36): 90-101.

5. Institute G (2012) Making abortion services accessible in the wake of legal reforms: a framework and six case studies. Guttmacher Institute, New York, USA.

6. Ahman E, Shah I (2011) Unsafe abortion: global and regional estimates of the incidence of unsafe abortion and associated mortality in 2003 In: ( $5^{\text {th }}$ edn), Sexual and reproductive health.

7. UNAIDS (2011) Securing the future today: synthesis of strategic information on HIV and young people. Joint United Nations Programme on HIV/AIDS, Geneva, Switzerland.

8. WHO (2006) Joint United Nations Programme on HIV/AIDS, AIDS epidemic update, December 2006, 2007. World Health Organization, Geneva, Switzerland.

9. Marston C, King E (2006) Factors that shape young people's sexual behaviour: a systematic review. The Lancet 368(9547): 1581-1586.

10. (2012) CSA, 2007 Population and Housing Census of Ethiopia.

11. MOH (2010) National Adolescent and Youth Reproductive Health Strategy 2010. Federal Democratic Republic of Ethiopia, Ethiopia.

12. Jima A (2012) Assessment of Knowledge, Attitude and Utilization of Emergency Contraception among Unmarried Women of Reproductive Age in Adama, Ethiopia. Health Science Journal, Ethiopia.

13. Feleke SA, Koye DN, Demssie AF, Mengesha ZB (2013) Reproductive health service utilization and associated factors among adolescents (15-19 years old) in Gondar town, Northwest Ethiopia. BMC Health Serv Res 13: 294.

14. Viner RM, Ozer EM, Denny S, Marmot M, Resnick M, et al. (2012) Adolescence and the social determinants of health. Lancet 379(9826): 1641-1652.

15. Taffa N (1998) Sexual activity of out of school youth, and their knowledge and attitude about STDs and HIV/AIDS in Southern Ethiopia. Ethiopia 17: 72.

16. Kelly MJ (2001) Challenging the challenger: understanding and expanding the response of universities in Africa to HIV/AIDS A synthesis report for the Working Group on Higher Education Association for the Development of Education in Africa [ADEA], p.82.

17. EFDRE, MOH (2015) The Federal Democratic Republic of Ethiopia Ministry of Health, Health Sector Transformation Plan.

18. Mengistu TS (2013) Risks for STIs/HIV infection among Madawalabu University students, Southeast Ethiopia: a cross sectional study. Reproductive health 10(1): 38.

19. Ndabarora E, Mchunu G (2014) Factors that influence utilisation of HIV/AIDS prevention methods among university students residing at a selected university campus. SAHARA J 11(1): 202-210.

20. Adam MB, Mutungi M (2006) Sexual risk behavior among Kenyan university students. Journal of the Arizona-Nevada Academy of Science 39(2): 91-98. 
21. Motuma A (2016) Utilization of youth friendly services and associated factors among youth in Harar town, east Ethiopia: a mixed method study. BMC Health Services Research 16(1): 272.

22. Tsegay G, Edris M, Meseret S (2013) Assessment of voluntary counseling and testing service utilization and associated factors among Debre Markos University Students, North West Ethiopia: a cross-sectional survey in 2011. BMC public health 13(1): 243.

23. Bam K (2015) Perceived sexual and reproductive health needs and service utilization among higher secondary school students in urban Nepal. American Journal of Public Health Research 3(2): 36-45.
24. Abebe M, Awoke W (2014) Utilization of Youth Reproductive Health Services and Associated Factors among High School Students in Bahir Dar, Amhara Regional State, Ethiopia. Open Journal of Epidemiology.

25. Tegegn A, Gelaw Y (2009) Adolescent reproductive health services in Jimma city: accessibility and utilization. Ethiopian Journal of Health Sciences 19(2).

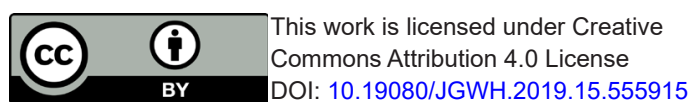

\section{Your next submission with Juniper Publishers will reach you the below assets}

- Quality Editorial service

- Swift Peer Review

- Reprints availability

- E-prints Service

- Manuscript Podcast for convenient understanding

- Global attainment for your research

- Manuscript accessibility in different formats

( Pdf, E-pub, Full Text, Audio)

- Unceasing customer service

Track the below URL for one-step submission https://juniperpublishers.com/online-submission.php 